\title{
Barfikste Kol Çekme Performansını Belirleyen Faktörlerin İncelenmesi
}

\author{
"Investigation of Factors Determining Pull Up Performance" \\ İbrahim Orkun AKCAN ${ }^{1} \quad \& \quad$ Cengiz ÖLMEZ $^{2} \quad$ \& $\quad$ Mehmet ÖZTAŞ3
}

\author{
ARAŞTIRMA MAKALESI \\ Tarihçe \\ Yayın Geliş Tarihi: 20 Ekim 2021 \\ Kabul Tarihi: 1 Kasım 2021 \\ Online Yayın Tarihi: 30 Aralık 2021
}

DOI: $\underline{\text { http://dx.doi.org/10.29228/anatoliasr.16 }}$

\section{Yazarlarla İletişim}

1- (Sorumlu Yazar) Erzincan Binali Yıldırım

Üniversitesi, Spor Bilimleri Fakültesi,

Erzincan, Türkiye

orkunakcan24@gmail.com

https://orcid.org/ 0000-0001-6983-2145

2- İl Milli Eğitim Müdürlüğü, Trabzon,

Türkiye

cengolmez@gmail.com

https://orcid.org/ 0000-0001-8584-6272

3- Erzincan Binali Yıldırım Üniversitesi, Spor

Bilimleri Fakültesi, Erzincan, Türkiye

oztasm24@gmail.com

https://orcid.org/0000-0003-4689-6490

\section{Yazar Katkıları}

Tüm yazarlar çalışmanın konseptine ve tasarımına katkıda bulundu.

\section{Finansman}

$\mathrm{Bu}$ çalışma herhangi bir kurum/kuruluştan maddi destek almadi.

\section{Çıkar Çatışması}

Yazarlar çıkar çatışması olmadığını beyan ediyorlar.

\section{Şeffaflık}

Yazarlar, çalışmada hiçbir hayati özelliğin ihmal edilmediğini, dürüst, doğru ve şeffaf bir anlatım ile raporlaştırıldığını ve herhangi bir tutarsızlık olmadığını beyan etmişlerdir.

Etik

$\mathrm{Bu}$ çalışmada bilimsel etik kriterlerine uyulmuştur.

\section{Referans Gösterimi}

Akcan, İ.O., Ölmez, C., Öztaş, M. (2021). Barfikste Kol Çekme Performansını Belirleyen Faktörlerin İncelenmesi, Anatolia Sport Research, 2(3): 1-9.

Copyright (C) 2021 by Anatolia Sport Research

\section{ÖZET}

Amaç: Bu araştırmanın amacı, düzenli egzersiz yapan bireylerin barfikste maksimum kol çekme performansını (MKÇ) belirleyen fiziksel ve motorik faktörlerin belirlenmesidir.

Materyal ve Metod: Araştırma, rekreatif düzeyde fakat düzenli olarak egzersiz yapan 117 erkek katılımcının gönüllü katılımı ile yapıldı. Katılımcıların fiziksel özelliklerinin tespit edilmesi amacıyla boy uzunluğu, vücut ağırlığı, vücut kitle indeksi ve vücut yağ yüzdesi değerleri incelendi. Katılımcıların motorik özelliklerinin tespiti için ise el kavrama kuvvetleri, bacak kuvvetleri, sırt kuvvetleri ve MKÇ performansları tespit edildi. Elde edilen MKÇ ölçüm sonuçlarına göre düşük performans (DP) ve yüksek performans (YP) grupları oluşturuldu. Gruplar arasındaki farklar incelenerek sonuçların güvenirliği test edildi. Elde edilen veriler tanımlayıcı ve ilişkisel analizlere tabi tutuldu, verilerin istatistiksel analizi için SPSS 25.0 istatistik programı kullanıldı ve 0.05 anlam düzeyinde incelendi.

Bulgular: Analiz sonuçları, katılımcıların barfikste kol çekme performansları ile fiziksel özellikleri arasındaki ilişkilerin anlamlı olduğunu $(\mathrm{p}<0.01)$, motorik performansları arasındaki ilişkilerin ise anlamlı olmadığını ( $\mathrm{p}>0.05)$ gösterdi. DP ve YP gruplarının fiziksel özellikleri arasındaki farkların istastistiksel olarak anlamlı $(\mathrm{p}<0.05)$, motorik özellikleri arasındaki farkların ise anlamlı olmadığı $(\mathrm{p}>0.05)$ tespit edildi.

Sonuç: Sonuç olarak, düzenli egzersiz yapan bireylerde boy uzunluğu vücut ağırlığı ve vücut yă̆ oranı gibi fiziksel faktörlerin barfikste kol çekme performansını etkileyen temel faktörler olduğu tespit edildi.

Anahtar Kelimeler: Barfiks, Kuvvet, Vücut Kompozisyonu

\section{ABSTRACT}

Purpose: The aim of this research is to determine the physical and motoric factors that determine the maximum pull-up performance (MKÇ) of individuals who exercise regularly.

Materials and Methods: The research was carried out with the voluntary participation of 117 male participants who exercise regularly but recreationally. In order to determine the physical characteristics of the participants, their height, body weight, body mass index and body fat percentage values were examined. In order to determine motoric characteristics of the participants, hand grip strength, leg strength, back strength and MKÇ performance were determined. According to the obtained MKÇ measurement results, low performance (DP) and high performance (YP) groups were formed. The reliability of the results was tested by examining the differences between the groups. The obtained data were subjected to descriptive and correlation analyzes, SPSS 25.0 statistical program was used for statistical analysis of the data and analyzed at 0.05 significance level.

Results: The results of the analysis showed that the correlations between the pull-up performances of the participants and their physical characteristics were significant $(p<0.01)$, but the correlations between their motoric performances were not significant $(p>0.05)$. It was determined that the differences between the physical characteristics of the DP and YP groups were statistically significant $(\mathrm{p}<0.05)$, while the differences between the motoric characteristics were not significant $(\mathrm{p}>0.05)$.

Conclusion: As a result, it was determined that physical factors such as height, body weight and body fat ratio were the main factors affecting the pull-up performance of individuals who exercise regularly.

Keywords: Body Composition, Pull-ups, Strength. 


\section{GíRiş}

Barfikste kol çekme, vücut ağırlığı ile ilişkili kassal dayanıklılığın ve kuvvet gelişiminin sağlanmasında sık kullanılan kalistenik ve çok eklemli bir üst vücut egzersizidir (Pate et al., 1993; Ronai and Scibek, 2014; Spiering et al., 2008). Barfikste kol çekme hareketi, bir bara tutunup asıldıktan sonra, tüm vücudun kollar yardımı ile yukarı doğru çekilmesini, kaldırılmasını gerektirir (Baker and Newton, 2004). Bu sebeple üst vücut kaslarını geliştirmede oldukça etkili fakat tüm vücudun taşınması sebebi ile diğer kalistenik egzersizlere göre direnç yükünün daha fazla olduğu bir egzersizdir (Romain and Mahar, 2009).

Barfikste kol çekme egzersizi yaygın olarak çocuklarda, ergenlerde ve askeri akademilerde bulunan kadın ve erkeklerde üst vücut kas kuvvetinin vücut yağ kütlesine oranını test etmek için kullanılmıştır (Harman et al., 2008; Johnson et al., 2009; Lusk et al., 2010; Pate et al., 1993; Ronai and Scibek, 2014). Kolluk kuvvetleri, askeriye ve yangınla mücadele gibi belirli mesleki gruplarda kişinin zor şartlarda vücudunu kaldırabilmesi veya taşıyabilmesi zorunlu bir ihtiyaçtır (Flanagan et al., 2003; Vanderburgh and Edmonds, 1997; Williford et al., 1999). Bu sebeple barfikste kol çekme hareketi sportif bir performans göstergesi olması yanında kolluk kuvvetleri, itfaiyeciler veya askerlerin mesleki yaşantılarında da sıklıkla uygulamak zorunda oldukları bir hareket ya da vücutlarını kaldırmak zorunda kaldıklarında başvurdukları bir tekniktir. Ayrıca barfikste kol çekme hareketi, bu tür meslek gruplarının seçme veya seçilme aşamalarında fiziksel performansı belirleyici bir ölçüm testi olarak da kullanılmaktadır (Engelman and MorrowJr, 1991).

Daha önce yapılan çalışmalarda sırt-omuz kuvveti ile barfikste kol çekme performansı arasındaki ilişkiler ya da benzer kalistenik ve direnç egzersizlerinde antropometrik ve vücut kompozisyonu değişkenlerinin etkisi incelenmişti (Esco et al., 2008; Halet et al., 2009; Johnson et al., 2009, 2009a). Barfikste asılı konumda vücudun taşınabilmesi artan kas kuvvetine bağlıdır. Fakat kas kütlesine ilave olarak artan vücut yağ kütlesi, performansı olumsuz etkilemektedir (Johnson et al. 2009; Vanderburgh and Edmonds 1997). Bu bulgular barfikste kol çekme ve üst vücut kuvvetinin ortak unsurlara sahip olduğunu göstermektedir. Fakat belirli oranlardaki vücut yağı kuvvet oluşumunu desteklerken, barfikste kol çekme performansı sırasında aynı zamanda taşınması gereken bir yük olmaktadır (Ölmez vd., 2019; Sterkowicz-Przybycień et al. 2011). Vücut yağ oranının kuvveti desteklemesi yönüyle bir avantajmı yoksa taşınması gereken bir yük olduğu için dezavantaj mı olduğu konusu hala aydınlatılmak zorunda olunan bir konudur.

Yapılan incelemede daha önce yapılmış çalışmaların; barfikste kol çekme performansı, vücut kompozisyonu ve kassal kuvvet ilişkileri üzerine yoğunlaştığı tespit edildi. Fakat barfikste kol çekme performansını belirleyen temel unsurlar, hangi unsurların daha etkin olduğu ve kuvvet seviyesi bakımından homojen gruplarda barfikste kol çekme performansını belirleyen asıl faktörlerin neler olduğu konuları hala araştırılmaya açık bir konudur. Bu çalışma ile elde edilecek bulgu ve sonuçlar kuvvet ve kondisyon koçları için önemlidir, çünkü vücudun bir barda yukarı doğru çekilmesi minimum beceri ve ekipman gerektirirken tüm vücut taşınmak zorundadır. Fakat kuvvet geliştirici diğer egzersiz türlerinde antrenman programı sırasında yükün bireyselleştirilmesine izin verilir. $\mathrm{Bu}$ özellik, iplere ve direklere tırmanma, yüzme, kürek çekme, jimnastik ve güreş gibi aktivitelerle ilgilenen birçok amatör ve profesyonelin maksimum güç ve kas dayanıklılı̆̆ kazanımlarını en üst düzeye çıkarmak için önemli bir faktör olabilir.

$\mathrm{Bu}$ çalışmada düzenli egzersiz yapan bireylerde maksimum barfikste kol çekme performasını etkileyen fiziksel ve motorik faktörler incelendi. Dolayısıyla bu araştırmanın amacı, barfikste kol çekme performansını belirleyen temel faktörlerin tespit edilmesidir. 


\section{MATERYAL VE METOD}

\section{Katılımelar}

Çalışma; son 1 yıllık süreçte minimum haftada 2 gün ve $90 \mathrm{dk}$. rekreatif olarak aerobik ve genel

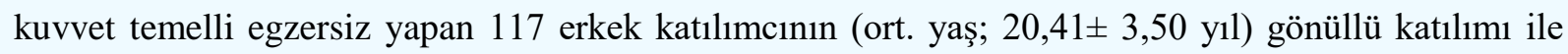
yürütüldü. Katılımcıların herhangi bir sağlık problemlerinin olmaması, sigara vb. tütün ürünleri kullanmamaları ve sürekli ilaç kullanmıyor olmaları araştırmaya katılmak için genel kriter olarak belirlendi. Tüm katılımcılar çalışmanın amacı, olası riskler ve yürütülecek süreç hakkında yazılı ve sözlü olarak bilgilendirildi, tüm soruları yanıtlandı, çalıșmanın herhangi bir evresinde ayrılma hakları olduğu hatırlatıldı. Çalışmaya katılım formu katılımcılar tarafından imzalandı. Çalışma, Helsinki Bildirgesine uygun olarak yürütüldü.

\section{Çalışma Prosedürü}

Çalışma, birbirini takip eden dört aşamada tamamladı.

1. aşamada; katılımcıların kayıt, bilgilendirme ve ön değerlendirme süreçleri tamamlandı. Çalışmaya katılım kriterlerine uymayan bireyler ( $\mathrm{n}=16)$, çalışma dışı bırakıldı.

2. aşamada; katılımcıların fiziksel özelliklerini oluşturan antropometrik ve vücut kompozisyonu ölçümleri yapıldı. Bu aşamada katılımcıların boy uzunluğu, vücut ağırlığı, vücut kitle indeksi ve vücut yağ yüzdeleri tespit edildi. Katılımcıların boy uzunlukları Holtain marka (İngiltere) stadiometre ile ölçüldü. Vücut ağırlığı, vücut kitle indeksi ve vücut yağı yüzdesi, ayaktan ayağa biyoelektirik impedans analizi (Tanita) ile kahvaltı öncesi 09.00-11.00 aralığında ölçüldü.

3. aşamada; katılımcıların motorik performans ölçümleri gerçekleştirildi. Katılımcıların motorik performanslarının tespit edilebilmesi amacı ile el kavrama kuvvetleri, sırt kuvvetleri, bacak kuvvetleri ve barfikste kol çekme performansları incelendi.

El kavrama kuvveti: Katılımcıların el kavrama kuvvetleri, ayakta dik durur pozisyonda, kol ve vücut arasındaki yaklaşık $45^{\circ}$ lik açıyla el kavrama dinamometresi (Takkei) kullanılarak ölçüldü (Heyward, 2002).

Sirt kuvveti: Katılımciların sırt kuvvetleri, sırt-bacak (Takkei) dinamometresi kullanılarak ölçüldü. Katılımcılar dinamometre sehpasına ayaklarını yerleştirdikten sonra, dizler ve kollar gergin, sırt düz ve gövde hafif öne eğik pozisyonda, elleri ile kavradıkları dinamometre barını dikey olarak maksimum oranda yukarı çekerek ölçümü gerçekleştirdi (Heyward, 2002).

Bacak kuvveti: Bacak kuvveti ölçümünde sirt-bacak (Takkei) dinamometresi kullanıldı. Katılımcılar, dizleri $130^{\circ}-140^{\circ}$ bükülü durumda dinamometre sehpasına ayaklarını yerleştirdikten sonra kollar gergin, sırt düz ve gövde hafif öne eğik pozisyonda, elleri ile kavradıkları dinamometre barını dikey olarak maksimum oranda yukarı çekerek testi tamamladılar. $\mathrm{Bu}$ test sırasında katılımcılara, dizlerini ekstensiyon pozisyonuna getirmeye çalışmaları, mümkün olduğunca kol ve sırt kuvvetini kullanmadan, sadece bacak kuvvetinden faydalanarak barı çekmek zorunda oldukları hatırlatıldı (Heyward, 2002).

Tüm kuvvet ölçümleri 3 defa tekrarlandı ve en iyi performans kg cinsinden kaydedildi. 
Maksimum Barfikste Kol Çekme Testi: Katılımcıların barfikste kol çekme tekrarları $190 \mathrm{~cm}$ yüksekliğinde ve $2,5 \mathrm{~cm}$ çapında bir barfiks demiri kullanılarak tespit edildi. Katılımcılardan, kolları omuz genişliğinde açıkken düz tutuş pozisyonunda (pençe tutuşu) barı kavradıktan sonra, çeneleri barfiks demirinin üzerine çıkana kadar kendilerini yukarı doğru çekmeleri ve daha sonra tekrar başlangıç pozisyonuna dönmeleri istendi. Her başarılı hareket 1 tekrar olarak kaydedildi (Şenduran ve Yabaş, 2020). Katılımcının pozisyonunu bozması ya da ayağının yerle teması sonucunda test sonlandirıld1.

4. aşamada; düşük performans (DP) ve yüksek performans (YP) grupları oluşturuldu. Elde edilen antropometrik, vücut kompozisyonu ve motorik ölçüm sonuçlarının, farklı barfikste kol çekme performansı sergileyen katılımcılardaki işlevselliklerinin değerlendirilmesi ve sonuçların güvenirliğinin test edilmesi amacıyla, DP ve YP grupları oluşturuldu. Grupların oluşturulma aşamasında, öncelikle tüm katılımcıların ortalama barfiks performansları tespit edildi. Ortama barfiks performansının altında kalan katılımcılar DP grubunu, üstünde kalanlar YP grubunu oluşturdu.

Araştırma sonunda DP ve YP grubu katılımcılarının fiziksel ve motorik ölçüm sonuçları arasındaki istatistiksel farklar incelendi ve yorumlandı.

\section{İstatistiksel Analiz}

Elde edilen tüm verilerin ortalama $(\overline{\mathrm{x}})$, standart sapma (Sd.), minimum ve maksimum değerleri, tanımlayıcı istatistikler ile tespit edildi. Verilerin normallikleri; basıklık-çarpıklık $(-1 /+1)$ aralıkları, histogram grafikleri ve Q-Q plot eğrileri ile kontrol edildi (Tabachnick and Fidell, 2013). Katılımcıların fiziksel özellikleri ile motorik ve maksimum barfikste kol çekme performansları arasındaki ilişkiler Pearson korelasyon analizi ile; DP ve YP grupları arasındaki istatistiksel farklar Independent Samples T-Test ile tespit edildi. Analizler SPSS 25 ile $\mathrm{p}<0.05$ anlamlılık düzeyinde yapıldi.

\section{BULGULAR}

Tablo 1. Katılımcıların fiziksel ve motorik özelliklerine ait tanımlayıcı bilgiler

\begin{tabular}{lccccc}
\hline & $\mathrm{N}$ & $\mathrm{X}$ & $\mathrm{Sd}$ & $\mathrm{Min}$. & Maks. \\
\hline Boy uzunluğu $(\mathrm{cm})$ & 117 & 178.32 & 5.70 & 165 & 193 \\
\hline Vücut ağırlı̆̆ı $(\mathrm{kg})$ & 117 & 73.12 & 7.95 & 57.00 & 99.60 \\
\hline VKİ (kg/m2) & 117 & 22.97 & 1.95 & 17.80 & 29.10 \\
\hline Vücut Yağ1 (\%) & 117 & 10.11 & 4.11 & 2.20 & 20.40 \\
\hline El kavrama- sağ (kg) & 117 & 61.72 & 9.01 & 43.60 & 84.60 \\
\hline El kavrama- sol (kg) & 117 & 59.11 & 8.59 & 40.00 & 82.00 \\
\hline Bacak kuvveti $(\mathrm{kg})$ & 117 & 113.72 & 24.88 & 43.50 & 174.00 \\
\hline Sirt kuvveti (kg) & 117 & 114.42 & 24.58 & 35.40 & 163.30 \\
\hline MKÇ (br.) & 117 & 10.96 & 2.45 & 4 & 18 \\
\hline
\end{tabular}

VKİ: Vücut kitle indeksi; MKÇ: Maksimum barfikste kol çekme

Katılımcıların boy uzunluğu, vücut ağırlı̆ğ, vücut kitle indeksi (VKİ), vücut yağ oranı, el kavrama kuvveti, bacak kuvveti, sırt kuvveti ve maksimum barfikste kol çekme (MKÇ) ölçüm ve performans değerleri tespit edildi (Tablo 1). 
Tablo 2. Katılımcıların fiziksel ve motorik özelliklerine ait değişkenlerin birbirleri ile ilişkileri

\begin{tabular}{|c|c|c|c|c|c|c|c|c|}
\hline & $\begin{array}{l}\text { Boy } \\
\text { uzunluğu } \\
(\mathrm{cm})\end{array}$ & $\begin{array}{l}\text { Vücut } \\
\text { ağırlığ1 } \\
(\mathrm{kg})\end{array}$ & $\begin{array}{l}\text { VKİ } \\
(\mathrm{kg} / \mathrm{m} 2)\end{array}$ & $\begin{array}{l}\text { Vücut yağı } \\
(\%)\end{array}$ & $\begin{array}{l}\text { El } \\
\text { kavrama- } \\
\text { sağ (kg) }\end{array}$ & $\begin{array}{l}\text { El } \\
\text { kavrama- } \\
\text { sol (kg) }\end{array}$ & $\begin{array}{l}\text { Baca } \\
\text { kuvveti } \\
(\mathrm{kg})\end{array}$ & $\begin{array}{l}\text { Surt } \\
\text { kuvveti } \\
(\mathrm{kg})\end{array}$ \\
\hline Vücut ağırlığı & $.616^{* *}$ & & & & & & & \\
\hline VKİ & 0.034 & $.806^{* *}$ & & & & & & \\
\hline Vücut yağ1 (\%) & 0.045 & $.531^{* *}$ & $.639^{* *}$ & & & & & \\
\hline El kavrama- sağ & $.314^{* *}$ & $.243^{* *}$ & 0.071 & -0.048 & & & & \\
\hline El kavrama- sol & $.309^{* *}$ & $.192^{*}$ & 0.007 & -0.147 & $.827^{* *}$ & & & \\
\hline Baca kuvveti & 0.142 & $.265^{* *}$ & $.227^{*}$ & 0.065 & $.383^{* *}$ & $.302^{* *}$ & & \\
\hline Sirt kuvveti & 0.055 & $.241^{* *}$ & $.262^{* *}$ & 0.120 & 0.164 & 0.138 & $.735^{* *}$ & \\
\hline MKÇ (br.) & $-.364^{* *}$ & $-.430^{* *}$ & $-.283^{* *}$ & $-.250^{* *}$ & -0.014 & 0.068 & -0.139 & -0.028 \\
\hline
\end{tabular}

**p<0.01; VKİ: Vücut kitle indeksi; MKÇ: Maksimum barfikste kol çekme

Katılımcıların boy uzunluğu, vücut ağırlı̆̆ı, VKİ, vücut yağ oranı, el kavrama kuvveti, bacak kuvveti, sırt kuvveti ve MKÇ ölçüm ve performans sonuçları arasındaki ilişkiler incelendi (Tablo 2). Analiz sonuçları MKÇ sonuçları ile antropometrik ve vücut kompozisyonu ölçüm sonuçları arasındaki ilişkilerin düşük düzeyde anlamlı olduğunu gösterdi $(\mathrm{p}<0.01)$.

Tablo 3. DP ve YP gruplarının fiziksel ve motorik özelliklerine ait karşılaştırma sonuçları

\begin{tabular}{|c|c|c|c|c|}
\hline Değişken & Grup & $\mathrm{X}$ & $\mathrm{Sd}$. & $\mathrm{p}$ \\
\hline \multirow{2}{*}{ Boy uzunluğu (cm) } & $\mathrm{DP}(\mathrm{n}=63)$ & 179,67 & 4,83 & \multirow{2}{*}{$0.005^{* *}$} \\
\hline & $\mathrm{YP}(\mathrm{n}=54)$ & 176,74 & 6,17 & \\
\hline \multirow{2}{*}{ Vücut ağırlığı (kg) } & DP $(n=63)$ & 75,90 & 7,95 & \multirow{2}{*}{$0.000 * *$} \\
\hline & $\mathrm{YP}(\mathrm{n}=54)$ & 69,86 & 6,66 & \\
\hline \multirow{2}{*}{ VKİ (kg/m2) } & $\mathrm{DP}(\mathrm{n}=63)$ & 23,50 & 2,10 & \multirow{2}{*}{$0.001 * *$} \\
\hline & $\mathrm{YP}(\mathrm{n}=54)$ & 22,34 & 1,55 & \\
\hline \multirow{2}{*}{ Vücut Yağı (\%) } & $\mathrm{DP}(\mathrm{n}=63)$ & 10,94 & 4,61 & \multirow{2}{*}{$0.016^{*}$} \\
\hline & $\mathrm{YP}(\mathrm{n}=54)$ & 9,15 & 3,23 & \\
\hline \multirow{2}{*}{ El kavrama- sağ (kg) } & $\mathrm{DP}(\mathrm{n}=63)$ & 61,75 & 9,07 & \multirow{2}{*}{0,972} \\
\hline & $\mathrm{YP}(\mathrm{n}=54)$ & 61,69 & 9,03 & \\
\hline \multirow{2}{*}{ El kavrama- sol (kg) } & $\mathrm{DP}(\mathrm{n}=63)$ & 58,95 & 9,18 & \multirow{2}{*}{0,834} \\
\hline & $\mathrm{YP}(\mathrm{n}=54)$ & 59,29 & 7,92 & \\
\hline \multirow{2}{*}{ Bacak kuvveti (kg) } & $\mathrm{DP}(\mathrm{n}=63)$ & 117,60 & 26,64 & \multirow{2}{*}{0.069} \\
\hline & $\mathrm{YP}(\mathrm{n}=54)$ & 109,20 & 22,04 & \\
\hline \multirow{2}{*}{ Sirt kuvveti (kg) } & DP $(n=63)$ & 115,41 & 27,14 & \multirow{2}{*}{0,637} \\
\hline & $\mathrm{YP}(\mathrm{n}=54)$ & 113,25 & 21,40 & \\
\hline \multirow{2}{*}{ MKÇ (br.) } & DP $(n=63)$ & 9,21 & 1,18 & \multirow{2}{*}{$0.000 * *$} \\
\hline & $\mathrm{YP}(\mathrm{n}=54)$ & 13,00 & 1,91 & \\
\hline
\end{tabular}

${ }^{*} \mathrm{p}<0.05 ; * * \mathrm{p}<0.01$; VKİ: Vücut kitle indeksi; MKÇ: Maksimum barfikste kol çekme

DP ve YP gruplarının boy uzunluğu, vücut ağırlı̆̆, VKİ, vücut yağ oranı, el kavrama kuvveti, bacak kuvveti, sırt kuvveti ve MKÇ ölçüm ve performans sonuçları arasındaki istatistiksel farklar incelendi (Tablo 3). Elde edilen sonuçlar, DP ve YP gruplarının el kavrama, bacak ve sırt kuvveti performansları arasındaki farkların anlamlı olmadığını ( $\mathrm{p}>0.05$ ), boy uzunluğu, vücut ağırlığı, VKİ, vücut yağ oranı ve MKÇ ölçüm ve performans sonuçları arasındaki farkların anlamlı olduğunu gösterdi $(\mathrm{p}<0.05)$. 


\section{TARTIŞMA VE SONUÇ}

$\mathrm{Bu}$ çalışmada, düzenli egzersiz yapan bireylerde maksimum barfikste kol çekme performasını etkileyen fiziksel ve motorik faktörler incelendi.

Fiziksel ve fizyolojik performans üzerinde antropometrik özelliklerin etkisi önemlidir (Ölmez vd., 2017; Yüksek vd., 2017). Artan vücut yağ oranı, harekete dayalı sportif performans1 olumsuz yönde etkilemektedir (Crawford et al., 2011; Spartali et al., 2014). Barfikste kol çekme hareketinde barda asılı pozisyonda iken tüm vücut ağırlığının kaldırılması gerekmektedir. Bu sebeple birey, vücut ağırlığını kaldırmanın gerektirdiği zorlukla başa çıkmalıdır (Romain and Mahar, 2009). Çalışmadan elde edilen sonuçlar, maksimum barfikste kol çekme performansı ile boy uzunluğu, vücut ağırlığı, vücut kitle indeksi ve vücut yağı oranı arasında negatif yönde anlamlı ilişkiler olduğunu gösterdi. Barfikste kol çekme hareketinin uygulanması sırasında, egzersiz yükünün tüm vücut ağırlığı olduğu düşünüldüğünde, kuvvet oluşumuna doğrudan katkısı olmayan tüm elementlerin, taşınması gereken fazla yükler olduğu ifade edilebilir. Japonyada üniversite öğrencileri üzerinde yapılan bir çalışmada, katılımcıların barfikste kol çekme tekrar sayıları ile vücut ağırlıkları ve vücut yağ yüzdeleri arasında negatif bir ilişki olduğu tespit edilmiştir (Branco et al., 2016). Flanagan et al. (2003) yapmış oldukları çalışmada, kız öğrencilere barfikste kol çekme egzersizi yaptırılırken vücut yağ yüzdelerinde azalma ve barfikste kol çekme tekrar sayılarında artış gözlemlendiğini rapor etmişlerdir. Sánchez Moreno ve diğerleri (2015), yapmış oldukları çalı̧̧mada, sporcuların barfikste kol çekme tekrar sayıları, lat çekişi tekrar sayıları, vücut ağırlıkları ve vücut yağ kütleleri arasındaki ilişkileri incelemişlerdir. Elde edilen sonuçlara göre barfikste kol çekme hareketinde vücut ağırlığı dezavantaj olmaktadır. Fakat her ne kadar lat çekişi ve barfikste kol çekme performansı arasındaki ilişkiler pozitif ve yüksek düzeyde olsa da lat çekişi sırasında vücut ağırlığının hareketin tekrar sayılarını etkilemediği ifade edilmiştir. Halet ve diğerleri (2009), yapmış oldukları çalışmada, sporcuların maksimum barfikste kol çekme performansları ile vücut ağırlığı ve vücut yağ oranı arasında negatif yönde ve düşük düzeyde anlamlı ilişkiler olduğunu rapor etmiş̧lerdir. Benzer şekilde Johnson ve diğerleri (2009), vücut kompozisyonu bileşenlerinin maksimum barfikste kol çekme performansını önemli düzeyde etkilediğini bildirmişlerdir. Ayrıca Vanderburgh ve Edmonds (1997), erkeklerde ağırlıksız barfikste kol çekme performansının, yağsız vücut kitlesinden çok vücut yağı ile ilişkili olduğunu öne sürmüşlerdir. Yaptıkları çalışmada Vanderburgh ve Edmonds, Vücut yağ oranındaki her \%10'luk artışın (yalnızca yağ kütlesinden kaynaklanan artış) barfikste kol çekme performansında \%53'lük bir azalmaya yol açacağını rapor ettiler. Benzer şekilde Woods ve diğerleri (1992), çalışmalarında, vücut ağırlı̆̆ı, vücut yağ yüzdesi ve boy uzunluğu değişkenleri ile maksimum barfikste kol çekme performansı arasında negatif yönde ve düşük- orta düzeyde anlamlı ilişkiler tespit etmişlerdir. Bu sonuçlar; boy uzunluğu, vücut yağ oranı ve vücut ağırlığı değişkenlerinin barfikste kol çekme performansını olumsuz yönde etkilediğini göstermektedir.

Çalışma sonuçlarına ait yapılan incelemede, maksimum barfikste kol çekme performansı ile kuvvet parametreleri arasındaki ilişkilerin anlamlı olmadığı tespit edildi. Ayrıca genel kuvvet seviyeleri bakımından homojen olan DP ve YP grupları arasındaki karşılaştırmalar, grupların anlamlı düzeyde farklı boy uzunluğuna ve vücut kompozisyonuna sahip olduklarını gösterdi. Düşük performans grubu daha uzun, ağır ve yağlı bir vücuda sahipti. Elde edilen sonuçlar, boy uzunluğu ve vücut kompozisyonunun barfikste kol çekme performansını belirleyen temel faktörlerden olduğunu göstermektedir. Thomas ve diğerleri (2021), barfikste kol çekme testinin üst vücut kuvvetini değerlendirmek için uygun bir test olduğunu bildirmişlerdir. Pate ve diğerleri (1993) ise yapmış oldukları çalışmada sporcuların barfikste kol çekme performansları ile bench press, kol bükme ve lat çekişi 1 maksimum tekrar (1RM) kuvvet düzeyleri arasında pozitif bir ilişki olduğunu fakat verilen 
değişkenlerin relatif kuvvetleri ile barfikste kol çekme performansları arasında anlamlı bir ilişki olmadığını rapor etmişlerdir. Johnson ve diğerleri (2009), yaptıkları çalışmada, erkek sporcuların 1RM barfikste kol çekme ve 1RM lat çekişi egzersizleri arasında pozitif yönde ve yüksek düzeyde anlamlı bir ilişki olduğunu, kadınlarda bu değişkenler arasında anlamlı bir ilişki olmadığını ve her iki cinsiyette de maksimum güç performansının, benzer kas dayanıklılık egzersizi kullanılarak tahmin edilebileceğini bildirmişlerdir. Fakat Halet ve diğerleri (2009), kadın sporcularda geleneksel (tekrar performansına dayalı) barfikste kol çekme performansı ile 1RM lat çekişi performansı arasında düşük düzeyde pozitif yönde anlamlı bir ilişki olduğunu ve geleneksel barfikste kol çekme performansı ile geleneksel (tekrar performansına dayalı) lat çekişi performansı arasında anlamlı bir ilişki olmadığını rapor etmişlerdir. Woods ve diğerleri (1992), yapmış oldukları çalışmada, sporcuların bench press, kol bükme ve lat çekişi 1RM performans toplamları ile barfikste kol çekme performansları arasında anlamlı bir ilişki olmadığını bildirmişlerdir.

Yapılan incelemede, kuvvet seviyesini gösteren farklı egzersiz türleri ile barfikste kol çekme performansı arasındaki ilişkilerin incelendiği daha önceki çalışmalarda, elde edilen sonuçların birbirini yeterince desteklemediği ve bu konuda daha fazla araştırma yapılması gerektiği anlaşılmaktadır. Her ne kadar çalışma sonuçları, barfikste kol çekme performansı ile el kavrama, sırt ve bacak kuvveti arasında anlamlı bir ilişki olmadığını gösterse de alanyazında bu bulguları destekleyen ve desteklemeyen bulgular mevcuttur. Vücudun barfiks barına doğru çekilebilmesinin kaslar vasıtasıyla sağlandığı düşünüldüğünde, kuvvet üretim oranının barfikste kol çekme performansını etkileyeceği aşikardır. Fakat barfikste kol çekme performansını belirleyen unsurların önem sırası belirlenirken, vücut kompozisyonunun önemli ve en büyük paya sahip olduğu anlaşılmatadır. Kuvvet ve barfikste kol çekme performansı arasındaki ilişkilerin düzeyini tespit edebilmek ve daha kesin sonuçlara ulaşabilmek için daha farklı kurgulara sahip araştırmalar yapılması gerekmektedir. Sonuç olarak, ilgili alanyazından ve çalışmadan elde edilen sonuçlar, fiziksel özelliklerin ve vücut kompozisyonunun barfikste kol çekme performansını belirleyen temel unsur olduğunu göstermektedir. Bu sonuçlar, sportif performans için vücut kompozisyonuna en az motorik performansı geliştirici egzersizler kadar önem verilmesi gerektiğini göstermektedir.

\section{KAYNAKLAR}

Baker, D. G., \& Newton, R. U. (2004). An analysis of the ratio and relationship between upper body pressing and pulling strength. Journal of Strength and Conditioning Research, 18(3), 594-598.

Branco, B. H. M., Diniz, E., Santos, J. F. S., Shiroma, S. A., \& Franchini, E. (2016). Normative tables for the dynamic and isometric judogi chin-up tests for judo athletes. Sport Sciences for Health, 1(13), 47-53. https://doi.org/10.1007/S11332-016-0331-8

Crawford, K., Fleishman, K., Abt, J. P., Sell, T. C., Lovalekar, M., Nagai, T., Deluzio, J., Rowe, R. S., McGrail, M. A., \& Lephart, S. M. (2011). Less body fat improves physical and physiological performance in army soldiers. Military Medicine, 176(1), 35-43. https://doi.org/10.7205/MILMED-D-10-00003

Engelman, M. E., \& MorrowJr, J. R. (1991). Reliability and skinfold correlates for traditional and modified pullups in children grades 3-5. Research Quarterly for Exercise and Sport, 62(1), 88-91. https://doi.org/10.1080/02701367.1991.10607523

Esco, M. R., Olson, M. S., \& Williford, H. (2008). Relationship of push-ups and sit-ups tests to selected anthropometric variables and performance results: A multiple regression study. Journal of Strength and Conditioning Research, 22(6), 1862-1868. https://doi.org/10.1519/JSC.0B013E318181FD03

Flanagan, S. P., Vanderburgh, P. M., Borchers, S. G., \& Kohstall, C. D. (2003). Training college-age women to perform the pull-up exercise. Research Quarterly for Exercise and Sport, 74(1), 52-59. https://doi.org/10.1080/02701367.2003.10609064

Halet, K. A., Mayhew, J. L., Murphy, C., \& Fanthorpe, J. (2009). Relationship of 1 repetition maximum lat-pull to pull-up and lat-pull repetitions in elite collegiate women swimmers. Journal of Strength and Conditioning Research, 23(5), 1496-1502. https://doi.org/10.1519/JSC.0B013E3181B338EC 
Harman, E. A., Gutekunst, D. J., Frykman, P. N., Nindl, B. C., Alemany, J. A., Mello, R. P., \& Sharp, M. A. (2008). Effects of two different eight-week training programs on military physical performance. Journal of Strength and Conditioning Research, 22(2), 524-534. https://doi.org/10.1519/JSC.0B013E31816347B6

Heyward, V. (2002). Advanced Fitness Assessment \& Exercise Prescription (4th ed.). Human Kinetics.

Johnson, D., Lynch, J., Nash, K., Cygan, J., \& Mayhew, J. L. (2009). Relationship of lat-pull repetitions and pull-ups to maximal lat-pull and pull-up strength in men and women. Journal of Strength and Conditioning Research, 23(3), 1022-1028. https://doi.org/10.1519/JSC.0B013E3181A2D7F5

Lusk, S. J., Hale, B. D., \& Russell, D. M. (2010). Grip width and forearm orientation effects on muscle activity during the lat pull-down. Journal of Strength and Conditioning Research, 24(7), 1895-1900. https://doi.org/10.1519/JSC.0B013E3181DDB0AB

Ölmez, C., Ayan, V., Yüksek, S., Öztaş, M., \& Civil, T. (2019). 11-13 yaş erkek taekwondo sporcularının somatotip yapıları ve performans özellikleri arasındaki ilişkinin incelenmesi. Ulusal Spor Bilimleri Dergisi, 3(1), 1-13.

Ölmez, C., Yüksek, S., Üçüncü, M., \& Ayan, V. (2017). The relationship between some anthropometric features and 50 meter freestyle swimming performance in 8-12 ages children. Turkiye Klinikleri, 9(3), 95-100. https://doi.org/10.5336/sportsci.2016-54026

Pate, R. R., Burgess, M. L., Woods, J. A., Ross, J. G., \& Baumgartner, T. (1993). Validity of field tests of upper body muscular strength. Research Quarterly for Exercise and Sport, 64(1), 17-24. https://doi.org/10.1080/02701367.1993.10608774

Romain, B., \& Mahar, M. (2009). Norm-referenced and criterion-referenced reliability of the push-up and modified pull-up. Measurement in Physical Education and Exercise Science, 5(2), 67-80. https://doi.org/10.1207/S15327841MPEE0502_1

Ronai, P., \& Scibek, E. (2014). The pull-up. Strength and Conditioning Journal, 36(3), 88-90. https://doi.org/10.1519/SSC.0000000000000052

Sánchez Moreno, M., Pareja Blanco, F., González Badillo, J. J., \& Díaz Cueli, D. (2015). Determinant factors of pull up performance in trained athletes. The Journal of Sports Medicine and Physical Fitness, 56(7-8), 825-833.

Spartali, I., Kostantinos, H., Ioannis, K., \& Thrasivoulos, P. (2014). Body fat percentage and body mass index as predictors of cadets' physical performance. The Open Sports Sciences Journal, 7(1), 53-59. https://doi.org/10.2174/1875399X01407010053

Spiering, B. A., Kraemer, W. J., Anderson, J. M., Armstrong, L. E., Nindl, B. C., Volek, J. S., \& Maresh, C. M. (2008). Resistance Exercise Biology. Sports Medicine, 38(7), 527-540. https://doi.org/10.2165/00007256-200838070-00001

Sterkowicz-Przybycień, K. L., Sterkowicz, S., \& Żarów, R. T. (2011). Somatotype, body composition and proportionality in polish top greco-roman wrestlers. Journal of Human Kinetics, 28(1), 154. https://doi.org/10.2478/V10078-011-0031-Z

Şenduran, F., \& Yabaş, F. (2020). Effects of the strength- and endurance based physical education programme on students' pull-ups and flexed-arm hang skills. International Journal of Physical Education Sport and Technologies, 1(1), 1-8.

Tabachnick, B. G., \& Fidell, L. S. (2013). Using multivariate statistics. Pearson.

Thomas, E., Gennaro, V., Battaglia, G., Bellafiore, M., Iovane, A., Palma, A., \& Bianco, A. (2021). Upper body strength endurance evaluation: A comparison between the handgrip strength and three body weight tests. Isokinetics and Exercise Science, 29(2), 185-191. https://doi.org/10.3233/IES-202206

Vanderburgh, P. M., \& Edmonds, T. (1997). The effect of experimental alterations in excess mass on pull-up performance in fit young men. Journal of Strength and Conditioning Research, 11(4), 230-233.

Williford, H. N., Duey, W. J., Olson, M. S., Howard, R., \& Wang, N. (1999). Relationship between fire fighting suppression tasks and physical fitness. Ergonomics , 42(9), 1179-1186. https://doi.org/10.1080/001401399185063

Woods, J. A., Pate, R. R., \& Burgess, M. L. (1992). Correlates to performance on field tests of muscular strength. Pediatric Exercise Science, 4(4), 302-311. https://doi.org/10.1123/PES.4.4.302 
Yüksek, S., Akpınar, E., Ayan, V., \& Ölmez, C. (2017). 14-16 yaş yüzücülerin antropometrik özellikleri ile sırtüstü yüzme performansları arasındaki ilişkinin incelenmesi. Istanbul Üniversitesi Spor Bilimleri Dergisi, 7(2), 1303-1414. 